\title{
A Relação entre a Educação e o Desenvolvimento Econômico no Brasil no Período de 1950 a 1970
}

\author{
The Relationship Between Education and Economic Development in Brazil \\ from 1950 to 1970
}

\section{La Relación entre Educación y Desarrollo Económico en Brasil de 1950 a 1970}

\author{
Lins, Maria Alcina Terto ${ }^{1}$ (Rio Grande, RS, Brasil)
}

ORCID ID: https://orcid.org/0000-0002-4900-020X

\begin{abstract}
Resumo
A subordinação da educação ao desenvolvimento econômico brasileiro entre os anos 1950 e 1970 revela elementos marcantes do movimento global capitalista, sobretudo ao evidenciar que o processo de acumulação de capital nos países centrais (denominados desenvolvidos) ocorre em detrimento do desenvolvimento dos países da América Latina, mediante uma relação fundada na exploração do trabalho legitimado pela regulação estatal. A industrialização brasileira e a respectiva complexificação do processo de trabalho exigiram uma força de trabalho especializada e modificações na organização educacional, cujos princípios de racionalidade, eficiência e produtividade constituiriam o eixo central na formação e/ou qualificação do trabalhador. A dinâmica de reprodução do capital utilizou a educação como um meio para adequar a capacidade produtora dos indivíduos sociais à manutenção do status quo da burguesia em favor dos setores dominantes, sob um insidioso discurso de modernização que ao invés de proporcionar o desenvolvimento econômico e social no Brasil, reafirmou a condição de dependência/subordinação aos países de capitalismo central.
\end{abstract}

Palavras-chave: Educação. Capitalismo. Desenvolvimento econômico. Modernização.

\begin{abstract}
The Education subordination to the Brazilian's economic development between 1950 and 1970 reveals remarkable elements of the global capitalist movement, mainly when it shows that in the central countries (denominated developed) capital's accumulation process occurs in detriment to the Latin American countries, due to a relation based on work exploitation legitimized by the state regulation. The Brazilian industrialization and the respective complexification of work processes demanded a specialized labor force and modifications on educational organization, whose rationality, efficiency, and productivity principles had constituted a centerline on the worker's formation and/or qualification. The dynamics of capital reproduction used education as a way to suit the productive capacity on the social subjects to the maintaining of bourgeoisie status quo in favor of dominant sectors, under an insidious discourse of modernization that instead of providing the Brazilian's economic and social development, reaffirmed its dependence/subordination to central capitalist countries.
\end{abstract}

Keywords: Education. Capitalism. Economic development. Modernization.

\begin{abstract}
Resumen
La subordinación de la educación al desarrollo económico brasileño entre los años 1950 y 1970 revela elementos marcantes del movimiento global capitalista, sobre todo al evidenciar que el proceso de acumulación de capital en los países centrales (denominados desarrollados) ocurre en detrimento del desarrollo de los países de América Latina mediante una relación basada en la explotación del trabajo legitimada por la regulación estatal. La industrialización brasileña y la respectiva complexión del proceso de trabajo exigieron una fuerza de trabajo especializada y modificaciones en la organización educativa, cuyos principios de racionalidad, eficiencia y productividad constituirían el eje central en la formación y/o cualificación del trabajador. La dinámica de reproducción del capital utilizó la educación como un medio para adecuar la capacidad productora de los individuos sociales al mantenimiento del status quo de la burguesía en favor de los sectores dominantes, bajo un insidioso discurso de modernización que en vez de proporcionar el desarrollo económico y social en Brasil, reafirmó la condición de dependencia/subordinación a los países de capitalismo central.
\end{abstract}

Palavras-Clave: Educación. Capitalismo. Desarrollo económico. Modernización.

${ }_{1}^{1}$ Assistente social, Professora Adjunta A na FSSO (UFAL). mariaalcinat@yahoo.com.br 


\section{Introdução}

A análise da organização educacional no Brasil só pode ser efetuada em suas múltiplas determinações quando inserida no movimento do capital em busca de novos campos de lucratividade. Visando a um ajustamento da relação capital/trabalho, a educação atrela-se ao setor produtivo como um mecanismo fundamental para a formação do trabalhador adequada às demandas da produção.

Ao se analisar o desenvolvimento econômico e social do país entre os anos 1950 e 1970, identifica-se que a propalada modernização da educação ancorou-se nas propostas da Agência para o Desenvolvimento Internacional do Departamento de Estado dos Estados Unidos da América (Usaid)². Sobre isso, concorda-se com os estudos realizados por Florestan Fernandes, que ao analisar o processo de desenvolvimento no Brasil, considerou-o como uma proposta de eternizar o país como uma nação dependente do capitalismo dos países centrais. No âmbito educacional, gestou-se uma incorporação das ideias do capital internacional, efetivando uma verdadeira subordinação não somente econômica, mas também ideológica.

Fernandes (1968) evidencia que, no âmbito das políticas sociais, à educação foi atribuído o papel de disseminar os valores culturais das elites metropolitanas, operacionalizando um ensino limitado. Uma educação condicionada às necessidades de qualificação da força de trabalho em conformidade com as configurações do processo de trabalho em diferentes setores produtivos, e não uma educação que proporcionasse o desenvolvimento da autonomia intelectual dos trabalhadores.

Vinculada ao campo do trabalho, a educação é um elemento importante no processo de acumulação de capital, uma vez que pode ser utilizada para difundir "um consenso que torna possível a reprodução do injusto sistema de classes", ou transformar-se em mercadoria. A deterioração do sistema público de ensino consequência dos cortes de recursos públicos - fortalece o processo de privatização da educação, funcional à lógica do consumo e do lucro (MÉSZÁROS, 2008, p. 15). 
A crítica à subordinação da educação ao processo de desenvolvimento é um componente estrutural na argumentação deste artigo, pois embora o discurso caracterizasse uma modernização da educação, o que se almejava era uma adequação da força de trabalho à expansão industrial. A mola propulsora desse insidioso desenvolvimento envolvia os ganhos na produtividade e não $o$ atendimento das necessidades humanas e sociais.

$\mathrm{Na}$ busca desenfreada pela acumulação, os capitalistas dos países centrais logo identificaram as potencialidades que um país como o Brasil poderia oferecer no âmbito da divisão internacional do trabalho; aqui estavam (e estão) disponíveis matéria-prima e força de trabalho a baixo custo. $\mathrm{A}$ isso se alia a função reguladora do Estado, a quem cabe regulamentar os acordos e as legislações necessárias para consolidar a extração de mais-valia. Investir em educação proporciona acúmulo de capital através de um menor custo do trabalho.

Tais análises convergem para a interpretação de que mediante investimentos estrangeiros, financiamentos externos e outros mecanismos reguladores, o Brasil vincula-se à economia estadunidense de maneira dependente e subordinada. Nessa estreita relação, o propósito modernizador na área da educação brasileira vem se configurando historicamente como um mecanismo institucional que insere os trabalhadores nas diferentes relações de produção sem provocar radicais alterações na dinâmica capitalista. Atribui-se à educação uma concepção produtivista, concebendo-a como um bem de produção e um agente de desenvolvimento.

\section{O desenvolvimento econômico em países de capitalismo dependente - a configuração brasileira}

No Brasil dos anos 1950 propagou-se a ideia de que a superação dos problemas econômicos e sociais poderia ser alcançada com o "desenvolvimento". Caberia ao processo de industrialização e de urbanização eliminar o suposto atraso do país e criar condições para solucionar os problemas nacionais, aproximando o capitalismo brasileiro ao capitalismo dos países centrais.

Os estudos de Florestan Fernandes são esclarecedores ao revelar que a questão do desenvolvimento não pode ser analisada de forma isolada; "ele deve ser encarado através de um grupo de sociedades que compartilhe um mesmo padrão de 
Programa de Pós-graduação em Educação, Universidade Federal do Ceará

Fortaleza-CE-Brasil

civilização, e as diferentes possibilidades que este oferece às sociedades que 0 compartilham [...]" (FERNANDES, 1968, p. 166). Para esse autor, as potencialidades de desenvolvimento estão intimamente relacionadas ao padrão de civilização. Numa "economia de mercado capitalista, fundada na ciência, na tecnologia científica", o ritmo de crescimento econômico é acelerado, diferentemente do que ocorre em sociedades com atividades industriais reduzidas (FERNANDES, 1968).

Outro elemento considerado determinante para que as mudanças sociais se concretizem é a posição das classes sociais na estrutura de poder da sociedade. "A luta pelo poder político representa uma luta pelo controle da mudança social" (FERNANDES, 1968). A disputa de poder político entre as nações pressupõe o direcionamento dado ao processo de desenvolvimento econômico e social. Nesse sentido, o Brasil tende a ser prejudicado porque se situa na periferia do processo civilizatório; nesta, a organização da vida econômica e social é extraída da "civilização ocidental moderna [...] controlada de fora e em função de interesses nacionais estranhos, por vezes incompatíveis ou em conflito com os próprios interesses nacionais" (FERNANDES, 1968, p. 168).

Ao discorrer sobre o ciclo ideológico do desenvolvimentismo no Brasil, Ricardo Bielschowsky (1988) afirma que a base para o desenvolvimento deveria ser a acumulação de capital na indústria, com a intervenção estatal planejando quais seriam os setores e os instrumentos promotores dessa expansão, além da captação de recursos financeiros. Nesta direção, sob o comando de Juscelino Kubitschek, o modelo desenvolvimentista progrediu, principalmente com 0 auxílio das multinacionais que investiram nos setores de bens de consumo e no setor industrial de base, e com o financiamento da esfera estatal.

Executando o Programa de Metas, o financiamento destinado aos setores de bens de consumo duráveis e à indústria de base contemplava recursos do orçamento federal (em média, 39,7\%), do orçamento dos Estados (com 10,4\%, inclusive fundos especiais), entidades públicas como o Banco Nacional de Desenvolvimento Econômico e o Banco do Brasil (com 14,5\%), e recursos próprios de empresas privadas ou de sociedade mista $(35,4 \%)$ (PRESIDÊNCIA DA REPÚBLICA, 1958).

A entrada de capital estrangeiro no Brasil possibilitou a realização de empréstimos através de bancos internacionais, evidenciando uma fusão de poder 
que articulava a burguesia brasileira, os capitalistas internacionais e o Estado.

Parafraseando Fernandes (1968, p. 170), ao se firmarem tais relações, "eterniza-se um ritmo da história que torna o Brasil uma nação moderna, mas do tipo 'colonial' e 'dependente'”. Corroborando a interpretação de Florestan, cita-se a contribuição de Ruy Mauro Marini (1973), que ao analisar o desenvolvimento do capitalismo na América Latina ressalta a relação de dependência em relação aos centros capitalista europeus:

No caso da industrialização europeia [...], o forte incremento da classe operária industrial e, em geral, da população urbana ocupada na indústria e nos serviços, que se verifica nos países industriais no século passado, não poderia ter acontecido se estes não contassem com os meios de subsistência de origem agropecuária, proporcionados de forma considerável pelos países latino-americanos [...]. Mas não se reduziu a isso a função cumprida pela América Latina no desenvolvimento do capitalismo: à sua capacidade para criar uma oferta mundial de alimentos, que aparece como condição necessária de sua inserção na economia internacional capitalista, prontamente será agregada a contribuição para a formação de um mercado de matérias-primas industriais, cuja importância cresce em função do mesmo desenvolvimento industrial [...]. A participação da América Latina no mercado mundial contribuirá para que o eixo da acumulação na economia industrial se desloque da produção de mais-valia absoluta para a de mais-valia relativa, ou seja, que a acumulação passe a depender mais do aumento da capacidade produtiva do trabalho do que simplesmente da exploração do trabalhador. (MARINI, 1973 [online] grifos nossos).

A inserção da América Latina na economia mundial ocorreu de maneira a afirmar um quadro de dependência entre as nações. Aos países latino-americanos caberia não apenas o fornecimento de matéria-prima industrial, mas, principalmente, a utilização da força de trabalho de maneira a acentuar os processos de exploração e opressão entre as classes sociais, visando ao aumento da produtividade e, consequentemente, ao acúmulo de capital.

As mudanças engendradas no cenário brasileiro sob 0 manto do desenvolvimentismo reforçam os interesses capitalistas, favorecendo o processo de consolidação do capitalismo industrial. A finalidade não era a melhoria das condições de vida e de trabalho dos trabalhadores. Ao invés de obter a autonomia nacional, o país foi convertido em sociedade de capitalismo dependente, cujas condições diferenciadas de desenvolvimento capitalista estão implicadas na própria história do desenvolvimento do modo de produção capitalista em sua tendência global. A dependência econômica é condicionada e regulada por vetores conjunturais e estruturais do mercado mundial. 


\section{A educação como estratégia de desenvolvimento social e econômico no contexto brasileiro no período de 1950 a 1960}

A busca pelo crescimento econômico e pelo desenvolvimento social dos países periféricos ${ }^{3}$ requer a operacionalização de reformas fiscais, tributárias e educacionais. O movimento dinâmico do capital em seu processo de desenvolvimento apropriou-se cada vez mais do setor dos serviços, submetendo-o às regras de mercado.

O capital em seu processo de valorização e acumulação precisa se apropriar de outras esferas lucrativas não só no âmbito da produção, mediante a exploração da força de trabalho e a consequente produção de mais-valia. O setor de serviços tem sido fundamental para sanar essa necessidade do capital, sempre amparado na atuação do Estado (seja por meio das mudanças na legislação, seja pelas formas de financiamento).

$\mathrm{Na}$ realidade brasileira dos anos 1950 e 1960, caracterizada pelo denominado capitalismo monopolista, houve uma expansão do capitalismo mediante o fortalecimento da industrialização do país, sob o discurso da Integração Nacional, que Oliveira (1977) analisou como uma "nacionalização do capital", um período marcado pela forte presença da propriedade estrangeira. $O$ crescimento da capacidade produtiva do setor de bens de produção e do setor de bens de consumo pressupunha um financiamento advindo do capital nacional (privado) e estrangeiro.

Por meio desses financiamentos, o Brasil, por sua condição de economia dependente, alcançou uma concentração de renda e de riqueza que exigiu a participação do Estado no financiamento da acumulação, diluindo os limites entre o público e o privado (OLIVEIRA, 1977). Nesse contexto ocorreram os acordos entre o Brasil e os Organismos Internacionais, pressupondo a necessidade de investimento nas políticas sociais. À política de educação foi atribuída a possibilidade de desenvolvimento econômico e social do país, cuja tônica se daria no ajustamento desta política ao novo padrão de acumulação, regulando-a pelo mercado.

\footnotetext{
${ }^{3}$ A condição de país periférico está intimamente ligada à questão da dependência entre países de capitalismo com desenvolvimento técnico estruturado, especializados em produtos industriais - considerados centrais - e os países considerados periféricos, demarcados pela produção de matéria-prima e intensificação da exploração da força de trabalho. Ambos são funcionais ao processo de acumulação e consolidação do capital.
} 
Programa de Pós-graduação em Educação, Universidade Federal do Ceará Fortaleza-CE-Brasil

Visando mascarar as desigualdades sociais e elidir superficialmente as diferenças de classe existentes tanto entre os denominados países periféricos em comparação aos países centrais, quanto nas realidades nacionais de cada país periférico, a educação foi adotada como uma estratégia para superar o subdesenvolvimento. No desenvolver desse processo histórico realizaram-se modificações no formato institucional, que sob a gestão do Estado possibilitou a consolidação de acordos e convênios financeiros internacionais, bem como a utilização dos recursos públicos para a manutenção dessas modificações nos diferentes níveis de escolarização.

Nas primeiras décadas do século XX, ao vivenciar mudanças políticas, econômicas e sociais em decorrência da sua passagem do sistema agrárioexportador para o sistema urbano-industrial, o Brasil apresentava um formato educacional que não atendia às necessidades econômicas com vistas ao desenvolvimento econômico e social (TEIXEIRA, 1989), devido às baixas taxas de diplomação escolar e à ausência de qualificação para o trabalho.

A modernização proposta teve como base as orientações norteamericanas: a educação seria um instrumento de aceleração do desenvolvimento e, no âmbito do ensino superior, caberia à Universidade estar a serviço da produção de uma força de trabalho adequada às necessidades do capital monopolista. As orientações estavam direcionadas para uma estrutura universitária baseada no modelo empresarial, cujas principais finalidades seriam o rendimento e a eficiência.

A concepção de educação que se estabeleceu foi a de uma educação enquanto matriz de integração, de caráter pragmático, cuja formação deveria ser rápida e adequada à indústria, apoiando a privatização do ensino e criando condicionalidades para o ensino público gratuito. A adoção de tal concepção subordinou, ainda mais, a educação brasileira às estratégias de desenvolvimento do capitalismo.

Assim, sob o pretexto de desenvolvimento, a educação foi definida como fator de produção, denominada como "capital humano", e de acordo com seu ideólogo seria capaz de "equalizar social, econômica e política(mente)" as classes sociais (FRIGOTTO, 2010). Realizando uma crítica ao conceito de capital humano, Frigotto esclarece que este consistia numa "quantidade ou grau de educação e de qualificação [...] indicativo de um determinado volume de conhecimentos, 
Programa de Pós-graduação em Educação, Universidade Federal do Ceará

Fortaleza-CE-Brasil

habilidades e atitudes adquiridas, que funcionam como potencializadoras da capacidade de trabalho e de produção" (FRIGOTTO, 2010, p. 43-44).

Disseminou-se então a programática ideológica de que 0 desenvolvimento econômico e social estaria atrelado ao processo de equalização do acesso ao ensino, o que exigiria um alto investimento na política educacional, estimulando a competitividade como princípio para o progresso e a suposta superação das desigualdades sociais entre as classes existentes no país. 0 combate às desigualdades mediante o crescimento econômico perpassaria a educação.

Numa astuciosa proposta de desenvolvimento econômico e social do Brasil, executou-se uma política desenvolvimentista cujo impulso modernizador baseava-se principalmente nas agências estatais norte-americanas, cujas teorias se pautavam pela defesa de investimento na formação de uma força de trabalho qualificada ao mercado, pois a "pobreza moral e intelectual do, ainda em formação, proletariado [...] seria um risco iminente de fratura social” (MOTA, 2008, p. 6).

As ideias desenvolvimentistas juntamente com a teoria do capital humano atribuíam à política de educação um estratégico papel de modernização, principalmente no que se referia à qualificação de força de trabalho, como "um instrumento de equalização entre países e regiões e entre classes; [e] um fator de superação das condições de pobreza (não só de renda, mas também da pobreza moral e cultural) da classe trabalhadora" (MOTA, 2008, p. 6).

A política de educação superior brasileira nos anos 1950/60 foi marcada por essa proposta de modernização, cujas linhas mestras se tornaram mais evidentes a partir do Golpe de $1964^{4}$, efetivando um movimento essencialmente antirreformista e anticomunista. Assim, estreitou laços com os Estados Unidos. No contexto da ditadura civil-militar, foram assinados os chamados acordos ${ }^{5}$ entre 0 Ministério da Educação (MEC) e a Agência para o Desenvolvimento Internacional (Usaid), objetivando desenvolver um programa para modernizar o sistema educacional brasileiro.

\footnotetext{
4 Trata-se do Golpe militar deflagrado contra o governo de João Goulart. O objetivo dos idealizadores do referido golpe seria a restauração da disciplina e da hierarquia nas Forças Armadas e a defesa do país contra a suposta ameaça comunista. Sobre esse momento histórico, Silva (2015) esclarece que o Golpe representou a vitória da burguesia nacional na defesa da internacionalização da economia e na consolidação de um modelo de desenvolvimento associado ao e dependente do capital internacional.

${ }_{5}$ Acordo MEC-USAID de Assessoria para a Modernização da Administração Universitária. Revisto dez meses depois, com outro título: Acordo MEC-USAID de Assessoria do Planejamento do Ensino Superior (PINA, 2011). 


\title{
O acordo MEC-Usaid como marco da privatização do ensino superior brasileiro
}

Há tempos, os Organismos Internacionais têm influenciado na área educacional brasileira. Nos anos 1960, os acordos econômicos com a Agência para o Desenvolvimento Internacional do Departamento de Estado dos Estados Unidos da América (Usaid), escancaravam a atuação desse organismo na configuração da política educacional.

O acordo MEC - Usaid evidenciou essa "cooperação" do governo com os organismos internacionais, adequando o sistema educacional ao modelo econômico da época, para que o Brasil superasse seus problemas de país subdesenvolvido. Para tanto, o acordo fundamentou-se em três princípios básicos:

\begin{abstract}
Educação e desenvolvimento, supondo que a educação escolar possibilitaria o desenvolvimento econômico social. Educação e Segurança, com a suposta ideologia da Segurança Nacional, solicitando a retirada das disciplinas com conteúdo político amplo (Filosofia, Sociologia, Psicologia), sob a suspeita de que ameaçava a segurança nacional. E Educação e Comunidade, que compreendia por comunidade a participação da sociedade civil nas decisões da escola. Entretanto, a criação dos Conselhos de educação era formada apenas por grupos de empresários. Nesse período, registra-se uma expansão do ensino superior privado. (ASSUNÇÃO, 2011).
\end{abstract}

Foi durante os governos de Castelo Branco e de Costa e Silva que se registrou a atuação da Usaid no planejamento do ensino brasileiro - do primário ao nível superior - desde empréstimos financeiros e custeio de técnicos para assessorar os países periféricos, até a assistência à educação universitária. Sob o discurso de modernização da administração universitária, o objetivo dos acordos era "gerar uma teia de dependências e de instrumentalidades, pela qual o talento jovem e a rede do ensino superior seriam submetidos aos dinamismos do sistema capitalista mundial de poder [...]" (FERNANDES, 1989, p. 141).

Tratava-se, na verdade, de uma incorporação das ideias do capital internacional, a efetivar uma subordinação da política de educação brasileira aos modelos educacionais norte-americanos, voltada às necessidades de mercado, tornando o país uma nação sem autonomia nem soberania educacional (FERNANDES, 1989). Efetivou-se assim uma política educacional que privilegiava o modelo americano de ensino produtivista, adequando a formação de força de trabalho brasileira às necessidades econômicas. 
Programa de Pós-graduação em Educação, Universidade Federal do Ceará Fortaleza-CE-Brasil

Os acordos realizados entre o MEC e a Usaid tiveram como eixo central o valor econômico que a educação poderia proporcionar ao processo produtivo, ao produzir um trabalho especializado fundamental à produção, imprimindo no trabalhador a ideia de que a mobilidade social dependia da sua produtividade no trabalho, fazendo-o acreditar que a qualificação profissional o colocaria num patamar elevado socialmente. Ao financiarem parte dos projetos de desenvolvimento educacional brasileiro, os Organismos Internacionais intensificaram suas ações no sentido de fornecer parâmetros educacionais adequados à lógica de valorização de capital mediante a apropriação do excedente econômico gerado pela força de trabalho barata.

De acordo com o relatório da Equipe de Assessoria ao Planejamento do Ensino Superior (1969), era necessário operacionalizar uma política nacional de educação que incentivasse a pesquisa científica, contando com o apoio do trinômio Estado - Universidade - Empresa, visando atender "aos imperativos da segurança, da ciência e da produtividade". Em conformidade com o Plano Atcon, essa proposta de estrutura administrativa para as universidades visava torná-las produtivas e eficientes.

A reestruturação administrativa universitária baseada no rendimento e na eficiência foi recebida com resistência pelo movimento estudantil, que reconheceu o caráter privatista e conservador atribuído a essa nova estrutura de universidade. A UNE como representante dos estudantes afirmava: "o governo militar propõe para a universidade uma universidade e um universitário inteiramente distantes e alienados dos problemas do seu país e do seu povo" (PINA, 2011, p. 68).

Entretanto, a resistência dos estudantes não foi suficiente para impedir a incorporação desses princípios conservadores na reorganização da estrutura universitária. Em meados de 1966, o governo aprovou o Decreto Lei no 53/66: "Art. 2. $\S 2$. O ensino e a pesquisa básicos serão concentrados em unidades que formarão um sistema comum para toda a Universidade", até ser sancionada a Lei $\mathrm{n}^{\circ}$ $5.540 / 68$, que, em seu texto legal, preconizava que o ensino superior seria ministrado em universidades, e excepcionalmente em estabelecimentos isolados de direito público ou privado.

Com a promulgação da Lei ํo 5.540/68 efetivou-se a reforma universitária do ensino superior no Brasil, realizando a unificação das unidades acadêmicas, 
transformando-as em Departamentos e anulando os movimentos de resistência estudantis. Ao incorporar os princípios da racionalização empresarial, contrários às demandas dos estudantes e da população em geral, a universidade foi organizada nos moldes de uma empresa capitalista moderna.

\section{Considerações finais}

As análises realizadas esclarecem que o dito desenvolvimento, refere-se ao desenvolvimento econômico capitalista, o que exige considerar as singularidades desse desenvolvimento econômico e a configuração das políticas sociais instituídas nos diferentes países, haja vista que o capitalismo, para sobreviver, desenvolve diferentes arranjos políticos e institucionais. Não se pode ignorar a forma históricoconcreta desse fenômeno modernizador, ou seja, não se podem desconsiderar as leis universais do movimento contraditório do capital.

Ao entender a educação como produto das relações sociais, e sendo essas relações marcadas pela base material capitalista, torna-se claro que a educação é também um espaço de contradições e, portanto, de disputas sociais. A relação entre os processos educacionais e a reprodução do capital evidencia a potencialidade da educação institucionalizada ao proporcionar uma força de trabalho adequada à expansão do modo de produção capitalista e ao disseminar valores que legitimam os interesses dominantes. Entretanto, considerando a dinamicidade do real e a correlação de forças entre as classes sociais, também é possível desenvolver uma educação cuja perspectiva emancipatória impulsione a organização e a luta por uma "ordem social metabólica radicalmente diferente" (MÉSZÁROS, 2008).

Ao propagar a estratégia da educação como centro do desenvolvimento, sob o discurso de enfrentamento da pobreza e propondo alternativas para o desenvolvimento dos países periféricos, acordos com Organismos Internacionais foram celebrados, efetivando formas de subordinar os processos educacionais aos interesses da reprodução das relações sociais capitalistas. O percurso histórico aqui reproduzido demonstra a incorporação e a efetivação dos princípios norteamericanos na política educacional brasileira, a partir de leis, decretos, reformas etc., atendendo às orientações de Organismos Internacionais para o desenvolvimento dos países periféricos, particularmente os latino-americanos. 
Programa de Pós-graduação em Educação, Universidade Federal do Ceará Fortaleza-CE-Brasil

Outro elemento importante nessas análises é a constatação de que a dinamização da economia capitalista ganha impulso (e sustentação) através da intervenção estatal, seja regulando a relação capital/trabalho, seja financiando o desenvolvimento do capital. Em momentos específicos, o Estado é a força propulsora para reaquecer a economia, pois vem desenvolvendo políticas sociais como um mecanismo de coesão social. Aquelas, ao atuarem sobre as consequências da exploração capitalista, funcionam como deslocadoras das contradições que se dão ao nível das relações de produção.

Observa-se também que a organização da educação articula-se ao projeto societário que se pretende implementar. Assim, ao longo da história brasileira, várias reformas na política de educação foram realizadas. Considerando o modelo econômico capitalista, tais reformas serviram (e servem) para consolidar as leis gerais desse modo de produção, cujas bases se sustentam na contradição, na exploração e na dominação de uma classe sobre a outra.

Particularmente no período investigado, a articulação do Brasil com o capital estrangeiro consolidou uma tendência tecnicista da educação direcionada para a produtividade e a eficiência - principalmente com a teoria do capital humano -, consolidando o vínculo entre mercado de trabalho e educação e realizando uma organização do sistema educacional a partir das orientações da política econômica norte-americana, a evidenciar uma relação de dependência entre Brasil e EUA.

Portanto, a suposta "modernização" da educação teve objetivos claros, direcionados ao retorno econômico e à melhoria da competitividade na economia mundializada, estreitando as relações entre a educação e a economia de mercado. Tal realidade cumpre a agenda estratégica do capital - em busca de nichos de mercado que possibilitem o aumento dos lucros -, mistificada nas expectativas de que assim haveria um desenvolvimento econômico e social nos países periféricos que se assemelharia ao dos países de capitalismo central.

\section{Referências Bibliográficas}

ASSUNÇÃO, Maria José. Reformas Educacionais de 1968 e 1971 e acordos MEC-USAID. 2011. Disponível em: http://www.universopedagogia Acesso em: 10 mai. 2014.

BIELSCHOWSKY, Ricardo. Pensamento econômico brasileiro: o ciclo ideológico do desenvolvimentismo. Rio de Janeiro: Contraponto, 1988. 
BRASIL. Lei no 5.540/68. Fixa normas de organização e funcionamento do ensino superior e sua articulação com a escola média, e dá outras providências. Senado Federal. Brasília.

FERNANDES, Florestan. Capitalismo dependente: classes sociais na América Latina. 4. ed. São Paulo: Global, 2009.

FERNANDES, Florestan. O desafio educacional. São Paulo: Cortez, 1989.

FERNANDES, Florestan. Sociedade de classes e subdesenvolvimento. Rio de Janeiro: Zahar Editores, 1968.

FRIGOTTO, Gaudêncio. Educação e a crise do capitalismo real. São Paulo: Cortez, 2010.

MARINI, Ruy Mauro. Dialética da Dependência. 1973. Disponível em: <https://www.marxists.org/portugues/marini/1973/mes/dialetica.htm> Acesso em: 20 out. 2017.

MÉSZÁROS, István. A educação para além do capital. 2. ed. São Paulo: Boitempo, 2008.

MOTA, Vania C. da. Gerar capital social: tarefa da "educação periférica" segundo Banco Mundial. In: Anais. 6o Seminário do Trabalho. 2008. Disponível em: <http://www.estudosdotrabalho.org/anais6seminariodotrabalho/vaniacardosodamotta .pdf> Acesso em: 23 fev. 2015.

OLIVEIRA, Francisco. O surgimento do antivalor: capital, força de trabalho e fundo público. In: Os direitos do antivalor: a economia política da hegemonia imperfeita. Rio de Janeiro: Vozes, 1998.

PINA, Fabiana. Acordo MEC-USAID: ações e reações (1966-1968). Dissertação apresentada à Faculdade de Ciências Letras de Assis. Universidade Estadual Paulista. 2011.

PRESIDÊNCIA DA REPÚBLICA. Programa de metas do presidente Juscelino Kubitschek. Serviço de documentação. Rio de Janeiro, 1958.

RELATÓRIO EAPES. Acordo MEC-Usaid. Ministério da Educação e Cultura. Rio de janeiro, 1969.

SILVA, Romeu Adriano da. Golpe Militar e adequação nacional à internacionalização capitalista (1964-1984). Disponível em: shttp://www.histedbr.fe.unicamp.br/navegando/periodo militar> Acesso em: 24 mar. 2015.

TEIXEIRA, Anísio. Ensino superior no Brasil: análise e interpretação de sua evolução até 1969. Rio de Janeiro: Editora da Fundação Getúlio Vargas, 1989. 186p. 

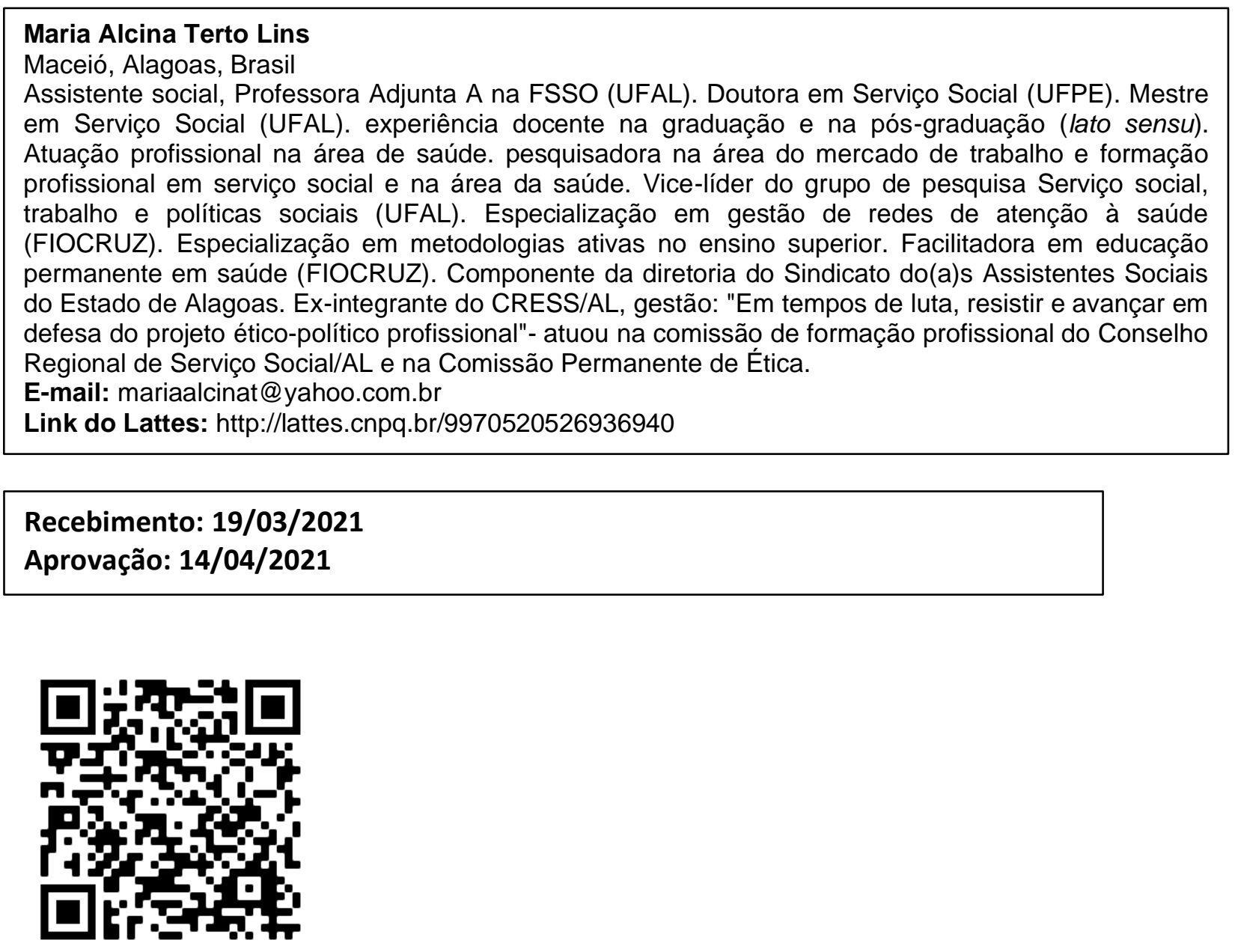

\section{Q.Code}

\section{Editores-Responsáveis}

Dr. Enéas de Araújo Arrais Neto, Universidade Federal do Ceará, UFC, Ceará, Brasil Dr. Sebastien Pesce, Universidade de Orléans, França 